\title{
A comparison of methods used to determine chewing side preference in deciduous, mixed and permanent dentitions
}

\author{
Comparação dos métodos usados para determinar o lado preferencial mastigatório nas dentições decídua, mista e permanente
}

Daphne Camara BARCELLOS ${ }^{1}$, Sergio Eduardo de Paiva GONÇALVES ${ }^{1}$, Melissa Aline SILVA ${ }^{2}$, Graziela Ribeiro BATISTA ${ }^{1}$, Patricia Rondon PLEFFKEN ${ }^{1}$, Alessandra Buhler BORGES ${ }^{1}$, César Rogério PUCCI ${ }^{1}$

1 - Institute of Science and Technology - UNESP - Univ Estadual Paulista - São José dos Campos (SP) - School of Dentistry - Department of Restorative Dentistry - São José dos Campos - SP - Brazil

\begin{abstract}
Objective: This study determined whether 'chewing side preference' (CSP) is correlated to 'chewing side preference during the first chewing cycle' $\left(\mathrm{CSP}^{\circ}{ }^{\circ} \mathrm{C}\right)$ in the deciduous, mixed and permanent dentitions. Methods: Three-hundred subjects were divided in 3 groups: Group 1 - 100 children 3-5 years old, primary dentition; Group 2 - 100 children 6-12 years old, mixed dentition; Group 3 - 100 subjects 18-47 years old, permanent dentition. CSP was determined using a method developed by McDonnell et al. Subjects were given a piece of gum and the position of the chewing gum was recorded 7 times as right or left. Subjects were classified as 'observed preferred chewing side' (OPCS) when they performed $5 / 7,6 / 7$ or $7 / 7$ strokes on the same side. OPCS corresponded to the CSP. $\mathrm{CSP} 1^{\circ} \mathrm{C}$ was determined using a method developed by Hoogmartens and Caubergh (1987). Subjects were given five pieces of gum and five pieces of bread and the position of the chewing gum at first chewing cycle was recorded as right or left. For each subject, an index (I) was performed. Chi-square $\left(\mathrm{X}^{2}\right)$ and phi correlation (r) tests were used to investigate significant correlations between CSP and $\operatorname{CSP} 1^{\circ} \mathrm{C}$. Results: There was a strong positive and significant correlation between CSP and $\operatorname{CSP} 1{ }^{\circ} \mathrm{C}$ for primary dentition ( $\mathrm{p}$ $=0.000 ; \mathrm{r}=0.82)$, for mixed dentition $(\mathrm{p}=0.000$; $\mathrm{r}=0.81)$ and a very strong positive and significant correlation for permanent dentition $(\mathrm{p}=0.000 ; \mathrm{r}=$ 0.90). Conclusion: CSP can be significantly correlated to $\operatorname{CSP} 1{ }^{\circ} \mathrm{C}$ for primary dentition, mixed dentition and permanent dentition, and these are strong positive relationships for primary and mixed dentitions and very strong positive relationship for permanent dentition.
\end{abstract}

\section{KEYWORDS}

Mastication; Deciduous dentition; Mixed dentition; Permanent dentition.

\section{RESUMO}

Objetivo: Este estudo determinou se o 'lado preferencial mastigatório' (LPM) é correlacionado com o 'lado preferencial no primeiro ciclo mastigatório' $\left(\mathrm{LP} 1^{\circ} \mathrm{CM}\right)$ nas dentições decídua, mista e permanente. Métodos: Trezentos indivíduos foram divididos em 3 grupos: Grupo 1 - 100 crianças de 3-5 anos, dentição primária; Grupo 2 - 100 crianças de 6-12 anos, dentição mista; Grupo 3 - 100 indivíduos de 18-47 anos, dentição permanente. O LPM foi determinado usando o método desenvolvido por McDonnell et al. Indivíduos recebiam um pedaço de goma de mascar e, durante a mastigação, foi anotado o lado (esquerdo ou direito) por 7 vezes. Os indivíduos foram classificados como 'lado preferencial mastigatório observacional' (LPMO) quando realizavam 5/7, 6/7 ou 7/7 mordidas do mesmo lado, correspondendo, portando, ao LPM. O LP $1^{\circ} \mathrm{CM}$ foi determinado usando o método desenvolvido por Hoogmartens e Caubergh. Os indivíduos recebiam 5 pedaços de goma de mascar e 5 pedaços de torrada, e a posição da primeira mordida foi anotada (esquerdo ou direito). Cada indivíduo recebeu um index (I). Os testes Qui-quadrado $\left(X^{2}\right)$ e Correlação de Phi (r) foram utilizados para avaliar as correlações significantes entre LPM e LP $1^{\circ} \mathrm{CM}$. Resultados: Houve forte e positiva correlação significante entre LPM e LP $1{ }^{\circ} \mathrm{CM}$ para as dentições decíduas $(\mathrm{p}=0,000 ; \mathrm{r}=$ $0,82)$, para dentição mista $(\mathrm{p}=0,000 ; \mathrm{r}=0,81)$ e muito forte e positiva para dentição permanente $(\mathrm{p}=0,000$; $r=0,90$ ). Conclusão: LPM pode ser significantemente correlacionado com $\mathrm{LP} 1^{\circ} \mathrm{CM}$ para todas as dentições, e essas correlações são fortes e positivas para as dentições decídua e mista e muito forte e positiva para a dentição permanente.

\section{PALAVRAS-CHAVE}

Mastigação; Dentição decídua; Dentição mista; Dentição permanente. 


\section{INTRODUCTION}

S

everal studies have been observed the prevalence of unilateral chewing in different populations [1-8]. "Unilateral chewing pattern" occurs when the number of masticatory cycles in one side is about $30 \%$ higher than the number of masticatory cycles performed on the opposite side $[9,10]$.

One method used to assess the unilateral chewingistoobservetheoccurrenceofthechewing side preference (CSP) $[1,11,1-8]$. CSP is defined when 'mastication is performed consistently or predominantly on the right or left side of the dentition' $[1,11]$. To assess the CSP, can be used the direct method by visual observation $[2,4]$ and indirect methods by electronic programs, such as cinematography, kinetography and computerized electromyography $[5,6,7,8,12]$. The direct method consists in the visual observation of the side that the bolus is positioned. This is a simple test, practical, fast and without misinterpretation. This method has more accurate than the indirect methods to assess CSP $[7,13]$.

The use of gum by the visual method to determine the CSP is preconized by several authors $[1,3,4,7]$, because it is a food inoffensive and inexpensive and easily accepted by children and adults. In addition, is easy to view during masticatory cycles, did no sprayed and it be more stable, with minimal changes in size and consistency [14]. In addition, Varela et al. [7] noted that there were no significant differences between the direct method with chewing gum and indirect method of kinesiography analysis to determine the CSP.

However, some authors state that if a CSP exists, it may be more pronounced during the first strokes, because a bolus of unknown consistency is tested by the neuromuscular system $[5,15,16]$. Hoogmartens and Caubergh [16] (1987) developed a simple method for reproducing chewing preference during the first chewing side $\left(\mathrm{CSP} 1^{\circ} \mathrm{C}\right)$ and concluded that $\mathrm{CSP} 1^{\circ} \mathrm{C}$ can be considered a new type of lateral preference. However, some studies have been used the first stroke to assed the CSP17,18, but there is no literature research that can state if $\mathrm{CSP} 1^{\circ} \mathrm{C}$ can be correlated with CSP in primary, mixed and permanent dentitions.
Searching for answers, this study investigated whether CSP is related to $\operatorname{CSP} 1^{\circ} \mathrm{C}$ in the primary, mixed and permanent dentitions. The null hypothesis tested was that the CSP was not associated with $\mathrm{CSP} 1^{\circ} \mathrm{C}$ in primary, mixed and permanent dentitions.

\section{MATERIAL AND METHODS}

\section{PARTICIPANTS}

This study was approved by the Research Ethics Committee of the São Jose dos Campos School of Dentistry - UNESP. A sample of 546 subjects was selected from a triage at the Department of Restorative Dentistry, from São José dos Campos School of Dentistry - UNESP according to the following inclusion criteria: both genders; stratification by age (3-5 years old - primary dentition; 6-12 years old - mixed dentition; adults aged $\geq 18$ years old - permanent dentition); not having been submitting to previous orthodontic or functional jaw orthopedic treatment; good general health; without neurological disorders; subjects at the permanent dentition stage had to have $\geq 24$ permanent teeth (excluding teeth extracted after surgical and/or orthodontic indications); children with primary dentition had to have $\geq 16$ primary teeth; without removable prosthetic restorations (acrylic- or metal-based) in one or both jaws.

The response rate was $80 \%(n=436)$. Reasons for non-participation were lack of interest $(50 \%)$, health problems $(19 \%)$, lack of time $(23 \%)$ and other reasons (8\%).

Of those who responded, 136 subjects were excluded. The exclusion criteria were: subjects with presence of oral pain (reports of pain, complaint of toothache, tenderness to percussion) and with presence of temporomandibular joint pain or orofacial muscle pain (reports of pain, complaint of discomfort or pain on palpation of condyles or orofacial muscles).

A total of 300 subjects were included in the calculations of the present study and were divided into three groups (n-100):

- Group 1 - 100 children 3-5 years old at the primary dentition stage;

- Group 2-100 children 6-12 years old at the mixed dentition stage;

- Group 3 - 100 subjects $18-47$ years old at the permanent dentition stage. 
One calibrated dentist was responsible for all of the dental and temporomandibular joint examinations. Four previously calibrated examiners were responsible for CSP and $\operatorname{CSP} 1^{\circ} \mathrm{C}$ tests. Training and consensus discussions were held before and during the study period. The intra-observer and inter-observer values showed almost perfect agreement, assessed by the Kappa coefficient (kappa values varied from 0.87 to 0.96).

\section{CHEWING SIDE PREFERENCE TEST}

The existence of a PCS was determined using a modified test, according to Mc Donnell et al.(2004) [4]. Subjects were given one piece of spearmint flavored Trident sugarless gum, fresh weight of about $1.8 \mathrm{~g}$ and size about $23 \mathrm{X}$ 18 X 4 mm (Adams Brazil, Bauru, São Paulo, Brazil). They did not know the purpose of the research. After a 15-second time interval, the evaluators asked subjects to stop chewing and to smile in order to observe on which side the gum was positioned (right or left). This procedure was repeated six times with a time interval of 5 seconds between procedures, totaling 7 strokes recorded as right or left.

The CSP of the subjects were classified according the follow criteria:

Consistent preferred chewing side (CPCS) - 7/7 strokes on the same side.

Predominant preferred chewing side (PPCS) $-5 / 7$ or $6 / 7$ strokes on the same side.

Observed preferred chewing side (OPCS) $5 / 7,6 / 7$ or $7 / 7$ strokes on the same side.

According to the Mc Donnell et al. [4]' classification, all subjects with CPCS or PPCSs had an OPCS, OPCS to the right or left corresponding to the CSP to right or left.

\section{CHEWING PREFERENCE DURING THE FIRST CHEWING SIDE TEST}

The existence of a PCS was determined using a method developed by Hoogmartens and Caubergh [16]. Subjects were given five pieces of spearmint flavored Trident sugarless gum (Adams Brazil) and five pieces of bread (Magic toast, Marilan Alimentos S/A, Marília, São Paulo, Brazil), of the same size as gum. The subjects were instructed to chew as normal on their posterior teeth. The position of the chewing bolus at first chewing cycle was observed by direct inspection and recorded (right or left). For each subject, an index (I) was performed: $I=(R$ $\mathrm{L}) /(\mathrm{R}+\mathrm{L})$, where $\mathrm{R}$ was the number of strokes performed to the right and $\mathrm{L}$ was the number of strokes performed to the left. A "significantly right" was when I $>0$, a "significantly left" was when $\mathrm{I}<0$ and "symmetrical" was when $\mathrm{I}=0$.

\section{STATISTICAL ANALYSES}

To determine the prevalence of CSP and $\operatorname{CSP} 1{ }^{\circ} \mathrm{C}$, descriptive statistics were used. Correlations between CSP and CSP $1^{\circ} \mathrm{C}$ were assessed by Chisquare (X2) analysis, at a level of significance of 0.05 or $5 \%$. The strength of correlation was assessed by the phi correlation coefficient $(r): r$ $\leq 0.19$ - very weak positive correlation; $0.20 \leq$ $r \geq 0.39$ - weak positive correlation; $0.40 \leq r$ $\geq 0.69$ - moderate positive correlation; $0.70 \leq$ $r \geq 0.89$ - strong positive correlation; and 0.90 $\leq r \geq 1$ - very strong positive correlation [19].

This correlation was done between presence of OPCS/CSP (right or left) and $\mathrm{CSP} 1^{\circ} \mathrm{C}$ (right or left), for example, right-OPCS and right-CSP $1^{\circ} \mathrm{C}$ subjects. However, subjects that have no CSP $(3 / 7$ or $4 / 7$ strokes on the same side) or have $\operatorname{CSP} 1^{\circ} \mathrm{C}$ classified as $\mathrm{I}=0$ were discarded.

Table 1 - Distribution of chewing side preference in Groups 1,2 and 3

\begin{tabular}{|c|c|c|c|c|c|c|c|c|}
\hline \multicolumn{9}{|c|}{ Classification } \\
\hline Group & CPCS/R & PPCS/R & OPCS/R & CPCS/L & PPCS/L & OPCS/L & NP & Total \\
\hline 1 & 29 & 25 & 54 & 17 & 16 & 33 & 13 & 100 \\
\hline 2 & 26 & 31 & 57 & 11 & 14 & 25 & 18 & 100 \\
\hline 3 & 8 & 32 & 40 & 12 & 24 & 36 & 24 & 100 \\
\hline
\end{tabular}

Legends: CPCS/R=Consistent preferred chewing side/Right; CPCS/L=Consistent preferred chewing side/Left; PPCS/R=Predominant preferred chewing side/Right; PPCS/ $\mathrm{L}=$ Predominant preferred chewing side/Left; $\mathrm{OPCS} / \mathrm{R}=$ observed preferred chewing side/Right; OPCS/L=0bserved preferred chewing side/Left; NP=Subjects preferred both sides. 
Table 2 - Distribution of Index of $\mathrm{CSP}^{\circ} \mathrm{C}$ in groups 1,2 e 3

\begin{tabular}{cccccccccccccc} 
Group & $\mathbf{1}$ & $\mathbf{+ 0 . 8}$ & $\mathbf{+ 0 . 6}$ & $\mathbf{+ 0 . 4}$ & $\mathbf{+ 0 . 2}$ & $\mathbf{0}$ & $\mathbf{- 0 . 2}$ & $\mathbf{- 0 . 4}$ & $\mathbf{- 0 . 6}$ & $\mathbf{- 0 . 8}$ & $\mathbf{- 1}$ \\
\hline 1 & 20 & 11 & 5 & 12 & 5 & 16 & 7 & 6 & 5 & 3 & 10 \\
2 & 29 & 10 & 9 & 5 & 4 & 18 & 4 & - & 4 & 7 & 12 \\
3 & 19 & 6 & 7 & 7 & 6 & 17 & 6 & 8 & 7 & 2 & 15
\end{tabular}

I» 0 means significantly right; | « 0 means significantly left; | =0 means absent or present on both sides (symmetrical).

Table 3 - Results of Chi-square $\left(\mathrm{X}^{2}\right)$ and Phi correlation tests for association between CSP and CSP1 ${ }^{\circ} \mathrm{C}$ in Groups 1,2 and 3

\begin{tabular}{|c|c|c|c|}
\hline Group & Correlation & Phicorrelation & $X 2 p$-value \\
\hline 1 & $\mathrm{CSP} \times \mathrm{CSP}^{10} \mathrm{C}$ & 0.82 & $0.000^{*}$ \\
\hline 2 & CSPXCSP10C & 0.81 & $0.000^{*}$ \\
\hline 3 & CSPXCSP10C & 0.90 & $0.000^{*}$ \\
\hline
\end{tabular}

*Significant Correlation.

\section{DISCUSSION}

This study investigated whether there is any association between CSP and $\mathrm{CSP} 1^{\circ} \mathrm{C}$ in primary.

In group 1, 49\% of the subjects were girls. The age ranged between 03-05 years of age (mean $=4.35$ years).

In group $2,59 \%$ of the subjects were girls. The age ranged between 06-12 years of age (mean $=8.88$ years).

In group 3, $71 \%$ of the subjects were women. The age-range was 18-47 years (mean $=23.68$ years).

\section{CHEWING SIDE PREFERENCE}

Table 1 shows the distribution of chewing side preference in Groups 1 (primary dentition), 2 (mixed dentition) and 3 (permanent dentition).

\section{Primary dentition}

$29 \%$ had a CPCS on the right; $25 \%$ had a PPCS on the right and sixteen; $54 \%$ in had an OPCS on the right and $33 \%$ on the left and 13\% preferred to chew on both sides.

\section{Mixed Dentition}

$26 \%$ had a CPCS on the right; $31 \%$ had a PPCS on the right; $57 \%$ had an OPCS on the right and $25 \%$ on the left and $18 \%$ preferred to chew on both sides.

\section{Permanent Dentition}

$12 \%$ had a CPCS on the left; $32 \%$ had a PPCS on the right; $40 \%$ had an OPCS on the right and $63 \%$ on the left and $24 \%$ preferred to chew on both sides.

\section{CHEWING PREFERENCE DURING THE FIRST CHEWING SIDE}

Table 2 shows the distribution chewing preference during the first chewing side in Groups 1 (primary dentition), 2 (mixed dentition) and 3 (permanent dentition).

\section{Primary dentition}

$53 \%$ had a $\operatorname{CSP} 1{ }^{\circ} \mathrm{C}$ on the right; $31 \%$ had a $\mathrm{CSP} 1{ }^{\circ} \mathrm{C}$ on the left and $16 \%$ preferred both sides (symmetrical).

\section{Mixed Dentition}

$57 \%$ had a $\mathrm{CSP}^{\circ} \mathrm{C}$ on the right; $25 \%$ had a $\mathrm{CSP} 1{ }^{\circ} \mathrm{C}$ on the left and $18 \%$ preferred both sides (symmetrical).

\section{Permanent Dentition}

$45 \%$ had a $\operatorname{CSP} 1{ }^{\circ} \mathrm{C}$ on the right; $38 \%$ had a $\mathrm{CSP} 1^{\circ} \mathrm{C}$ on the left and $17 \%$ preferred both sides (symmetrical).

\section{CORRELATION BETWEEN CSP AND CSP $1^{\circ} \mathrm{C}$}

Table 3 shows the results of the Chi-square (X2) and phi correlation (r) tests for the correlation between CSP and $\operatorname{CSP} 1^{\circ} \mathrm{C}$ in Groups 1 (primary dentition), 2 (mixed dentition) and 3 (permanent dentition).

\section{Primary dentition}

There was a significant correlation between CSP and $\operatorname{CSP} 1^{\circ} \mathrm{C}(\mathrm{p}=0.0000)$ and a strong positive correlation $(\mathrm{r}=0.82)$. 


\section{Mixed Dentition}

There was a significant correlation between CSP and $\operatorname{CSP} 1^{\circ} \mathrm{C}(\mathrm{p}=0.0000)$ and a strong positive correlation $(r=0.81)$.

\section{Permanent Dentition}

There was a significant correlation between CSP and $\operatorname{CSP} 1{ }^{\circ} \mathrm{C}(\mathrm{p}=0.0000)$ and a very strong positive correlation $(\mathrm{r}=0.90)$.

\section{DISCUSSION}

This study investigated whether there is any association between $\mathrm{CSP}$ and $\mathrm{CSP} 1^{\circ} \mathrm{C}$ in primary, mixed and permanent dentition. CSP occurs when over $70 \%$ of the masticatory cycles are performed on the same side $[9,10]$. According to Mc Donnell et al. [4], subjects have 2 classifications: CPCS when they chewed $7 / 7$ times on the same side (100\% of the masticatory cycles occur on the same side); PPCS - when they chewed $5 / 7$ or $6 / 7$ times on the same side ( $71.4 \%$ of the masticatory cycles occur on the same side). The term OPCS was used when the subjects were classified as CPCS or PPCS. Therefore, OPCS corresponded to CSP (CSP/OPCS $=$ CPCS plus PPCS).

The prevalence of a CSP in children with deciduous dentition (87\%) and with mixed dentition $(82 \%)$ is similar with the findings of McDonnell et al.4 that observe 92\% of CSP in children with mixed dentition. A higher prevalence of a CSP in children (deciduous and mixed dentition) compared to adults was expected because children had in difficulties lateralizing food smoothly and efficiently $[19,20]$. It was expected, therefore, that they would have difficulty moving a bolus from one side of the mouth to the other and would therefore be more likely to chew on one side, and this preference tends to disappear with age $[4,19,20]$. The prevalence of CSP in subjects with permanent teeth (76\%) is similar to the findings of Christensen and Radue [1], Pond et al. [2], Kazazoglu et al. [3], Varela et al. [7], Nissan et al. [17], Reinhardt et al. [12], Martinez-Gomis et al. [8] , Nissan et al. [18], who reported prevalence of CSP, respectively: $68 \%, 77.8 \%$, 88\%, 88.4\%, 97.4\%, 78\%, 63.24\% and $97.9 \%$.
The distribution of the CSP/OPCS in children at the primary dentition stage was $54 \%$ to the right and $33 \%$ to the left; in children at the mixed dentition stage it was $57 \%$ to the right and $25 \%$ to the left; and in subjects with permanent dentition was $40 \%$ to the right and $36 \%$ to the left. The results of this study confirm the findings of Shiere and Manly [21], who concluded that 'among children the tendency to prefer the right side predominates over the tendency to prefer the more efficient side' $[9,20]$. Furthermore, the results of the present study are consistent with the findings of Christensen and Radue [6], Varela et al. [21], Nissan et al. [2], Diernberger et al. [7] and Martinez-Gomis et al. [11], Nissan et al. [14] who observed a higher prevalence of CSP to the right in adults with permanent dentition.

Also, this study demonstrated a higher prevalence of subjects who preferred to chew during the first chewing cycle on the right compared on the left, regardless type of dentition evaluated: $53 \%$ of children with deciduous dentition, $57 \%$ of children with mixed dentition and $45 \%$ subjects with permanent dentition were "significant right". Delport et al. [15] found the proportion of $60 \%$ of subjects (permanent dentition) who performed the first chewing cycle on the right side and $40 \%$ on the left. Hoogmartens and Caubergh [16] observed that $56.25 \%$ of subjects (permanent dentition) realized the first chewing cycle on the right side, $31.25 \%$ on the left side and $12.5 \%$ had rates equal to the left and right sides. Nissan et al. [17] and Nissan et al. [18] observed that, respectively, $73 \%$ and $78.3 \%$ of the subjects had first cycle masticatory on the right side and $27 \%$ and $19.1 \%$ on the left side. Our results corroborate the results of these researches, because there is higher prevalence of preferred right side in the first chewing cycle, regardless of the dentition evaluated.

Chewing preference is an innate quality, centrally controlled and can be affected by social and personal learning $[11,17]$. Furthermore, Hoogmartens and Caubergh [11] stated that chewing preference could be determined from the peripheral reflex system, which is often proposed to explain other lateral preferences. Diernberger et al. [22] believe that how the 
right side is generally chosen, irrespective of peripheral factors, indicates that chewing preference may be determined by central nervous system mechanisms, because there is higher frequency of right-sidedness in the population.

The null hypothesis was rejected, because there was a significant correlation between CSP and $\operatorname{CSP} 1^{\circ} \mathrm{C}$ in primary dentition $(\mathrm{p}=0.000$; $r=0.82)$ and in mixed dentition $(p=0.000$; $\mathrm{r}=0.81$ ), and these were a strong positive correlations. In addition, our results showed that there was a significant correlation between CSP and $\operatorname{CSP} 1^{\circ} \mathrm{C}$ in permanent dentition $(\mathrm{p}=$ $0.000 ; r=0.90)$, and this was a very strong positive correlation.

The musculature of the stomatognathic system has a greater power on the working side, whereas on the non-working side the musculature has become more elongated and lowered tone [10]. The first chewing stroke is realized when the subject unknown the consistency of food. Thus, the subject uses the side of more efficiency to start the masticatory cycle, characterized by work side or preferred chewing side. Therefore, the preferred chewing side is always more pronounced during the first chewing cycle [15].

According to Delport et al. [15], when subjects choose continuously the same side to performed the first chewing cycle, it can concluded that this is the preferred chewing side. The results of this study confirmed the findings of Kazazoglu et al. [3], who also noted a strong relationship between the first chewing cycle and chewing side preference, which was coincident in $75 \%$ of the population. Additionally, Nissan et al. [17] (2004) and Nissan et al. [18] (2011) considered that first chewing cycle determines presence of the CSP.

The results of this study are very relevant to clinical practice and demonstrated that to determine the CSP in primary, mixed and permanent dentitions, it can be used the visual observation in the first chewing cycle. Also, CSP may be determined by visual observation at different chewing cycles.

However, the preferred side in the first chewing cycle is directly related to the unilateral chewing pattern $[19,20]$. Evaluation of chewing side preference should be part of the routine dental examinations, especially in primary and mixed dentitions. The unilateral chewing pattern cannot be an acceptable standard in children, because chewing plays a significant role in craniofacial development, periodontal tissue stability, occlusion harmony, orofacial muscle development, stimulus in the eruption of teeth and increase in dental arch dimensions [23,24]. The early diagnosis of the presence of the CSP, particularly in an exclusively or consistent preferred chewing side pattern, may prevent the unilateral chewing pattern from triggering various consequences in the stomatognathic system in adulthood [25].

\section{CONCLUSION}

According to the methodology used, it can be conclude that the CSP is correlated with $\operatorname{CSP} 1^{\circ} \mathrm{C}$ in the deciduous, mixed and permanent dentition

\section{REFERENCES}

1. Christensen LV, Radue JT. Lateral preference in mastication: a feasibility study. J Oral Rehabil. 1985; 12:421-7.

2. Pond LH, Barghi N, Barnwell GM. Oclusion and chewing side preference. J Prosthet Dent. 1986; 55: 498-500.

3. Kazazoglu E, Heath MR, Müller F. A simple test for determination of the preferred chewing side. J Oral Rehabil. 1994; $21: 723$.

4. Mc Donnell ST, Hector MP, Hannigan A. Chewing side preferences in children. J Oral Rehabil. 2004; 31: 855-60.

5. Christensen LV, Radue JT. Lateral preference in mastication: an electromyographic study. J Oral Rehabil. 1985;12:429-34.

6. Christensen LV, Rassouli NM. Experimental occlusal interferences. Part I. a review. J Oral Rehabil. 1995;22:515-20.

7. Varela JM, Castro NB, Biedma BM, Da Silva Domínguez JL, Quintanilla JS, et al. A comparison of the methods used to determine chewing preference. J Oral Rehabil. 2003;30:990-4.

8. Martinez-Gomis J, Lujan-Climent M, Palau S, Bizar J, Salsench J, Peraire M. Relationship between chewing side preference and handedness and lateral asymmetry of peripheral factors. Arch Oral Biol. 2009; 54:101-7.

9. Mongini F. Temporomandibular joint and muscles cranio cervicofacial: pathophysiology and treatment. São Paulo: Santos; 1998.

10. Bianchini EMG. Mastication and temporomandibular joint: evaluation and therapy in fonoaudiology fundaments. Rio de Janeiro: Guanabara Koogan; 1998. 
11. Hoogmartens MJ, Caubergh MAA. Chewing side preference in man correlated with handedness, footness, eyedness and earedness. Electromyogr Clin Neurophysiol. 1987;27:293-300.

12. Reinhardt R, Tremel T, Wehrbein H, Reinhardt W. The unilateral chewing phenomenon, occlusion, and TMD. Cranio. 2006;24:166-70.

13. Okamoto A, Hayasaki H, Nishijima N, Iwase Y, Yamasaki Y, Nakata M. Occlusal contacts during lateral excursions in children with primary dentition. J Dent Res. 2000;79:1890-5.

14. Shiga H, Kobayachi Y, Arakawa I, Shonai Y. Selection of food and chewing side for evaluating masticatory path stability. Odontology. 2003:91:26-30.

15. Delport HP, de Laat A, Nijs J, Hoogmartens MJ. Preference pattern of mastication during the first chewing cycle. Electromyogr Clin Neurophysiol. 1983;23:491-500.

16. Hoogmartens MJ, Caubergh MAA. Chewing side preference during the first chewing cycle as a new type of lateral preference in man. Electromyogr Clin Neurophysiol. 1987;27:3-6.

17. Nissan J, Gross MD, Shifman A, Tzadok L, Assif D. Chewing side preference as a type of hemispheric laterality. J Oral Rehabil. 2004;31:412-6.

18. Nissan J, Berman 0, Gross 0, Haim B, Chaushu G. The influence of partial implant-supported restorations on chewing side preference. J Oral Rehabil. 2011;38:165-9.
19. Gisel EG, Schwaab L, Lange-Stemmler L, Niman CW, Schwartz JL. Lateralization of tongue movements during eating in children 2 to 5 years old. Am J Occup Ther. 1986; 40: 265-70.

20. Gisel EG.Development of oral side preference during chewing and its relation to hand preference in normal 2- to 8-year-old children. Am J Occup Ther. 1988;42:378-83.

21. Shiere FR, Manly RS. The effect of the changing dentition on masticatory function. J Dent Res. 1952;31(4):526-34.

22. Diernberger S, Bernhardt O, Schwahn C, Kordass B. Diernberger S, Bernhardt 0, et al. Self-reported chewing side preference and its associations with occlusal, temporomandibular and prosthodontic factors: results from the population-based Study of Health in Pomerania (SHIP-0). J Oral Rehabil. 2008;35(8):613-20.

23. Ramfjord S, Ash MM. Occlusion. Philadelphia: WB Saunders; 1983.

24. Larato DS. Effects of unilateral mastication on tooth and periodontal structures. J Oral Med. 1970;25(3):80-3.

25. Barcellos DC, da Silva MA, Batista GR, Pleffken PR, Pucci CR, Borges $A B$, et al. Absence or weak correlation between chewing side preference and lateralities in primary, mixed and permanent dentition. Arch Oral Biol. 2012 Aug;57(8):1086-92.

\section{Daphne Camara Barcellos \\ (Corresponding address)}

Avenida Engenheiro Francisco José Longo, 777, Jardim São Dimas, São José dos Campos, SP,

Brazil, CEP: 12245-000

Received: 2012 Dez 10

E-mail address: daphnecbarcellos@hotmail.com 